From St Bartholomew's Hospital; Cancer Research UK and UCL Cancer Trials Centre; University College Hospitals Trust; Royal Marsden Hospital; Guy's and St Thomas' NHS Trust; and Medical Research Council Clinical Trials Unit, London; Clatterbridge Centre for Oncology, Wirral; Weston Park Hospital, Sheffield; Cancer Research UK Oncology Unit, Southampton General Hospital, Southampton; Norfolk and Norwich University Hospital, Norfolk; and Ninewells Hospital, University of Dundee, Dundee, United Kingdom.

Submitted March 4, 2004; accepted October 6, 2004.

Supported in part by the London Lung Cancer Group London, UK (registered charity No. 1074994), which received funding from Lilly Oncology to support this trial.

Authors' disclosures of potential conflicts of interest are found at the end of this article.

Address reprint requests to Nicole Gower, London Lung Cancer Group, Cancer Research United

Kingdom and University College London Cancer Trials Centre, 158-160 N Gower St, London NW1 2ND, United Kingdom e-mail: ng@ctc.ucl.ac.uk.

() 2005 by American Society of Clinical Oncology

0732-183X/05/2301-142/\$20.00

DOI: $10.1200 / J C O .2005 .03 .037$

\title{
Gemcitabine Plus Carboplatin Versus Mitomycin, Ifosfamide, and Cisplatin in Patients With Stage IIIB or IV Non-Small-Cell Lung Cancer: A Phase III Randomized Study of the London Lung Cancer Group
}

R.M. Rudd, N.H. Gower, S.G. Spiro, T.G. Eisen, P.G. Harper, J.A.H. Littler, M. Hatton,

P.W.M. Johnson, W.M.C. Martin, E.M. Rankin, L.E. James, W.M. Gregory, W. Qian, and S.M. Lee

$$
\begin{array}{llllllll}
\text { A } & \text { B } & \text { S } & \text { T } & \text { R } & \text { A } & \text { C } & \text { T }
\end{array}
$$

\section{Purpose}

This phase III randomized trial (ISRCTN 52253218) compared two chemotherapy regimens, gemcitabine plus carboplatin and mitomycin, ifosfamide, and cisplatin, in chemotherapynaive patients with advanced non-small-cell lung cancer (NSCLC). The regimens were compared with regard to effects on survival, response rates, toxicity, and quality of life.

\section{Patients and Methods}

Eligible patients had previously untreated stage IIIB or IV NSCLC suitable for cisplatin-based chemotherapy. Randomly assigned patients were to receive four cycles, each at 3-week intervals, of carboplatin area under the curve of 5 on day 1 plus gemcitabine $1,200 \mathrm{mg} / \mathrm{m}^{2}$ on days 1 and $8(\mathrm{GCa})$ or mitomycin $6 \mathrm{mg} / \mathrm{m}^{2}$, ifosfamide $3 \mathrm{~g} / \mathrm{m}^{2}$, and cisplatin $50 \mathrm{mg} / \mathrm{m}^{2}$ on day 1 (MIC).

\section{Results}

Between February 1999 and August 2001, 422 patients (GCa, $n=212$; MIC, $n=210$ ) were randomly assigned in the United Kingdom. The majority of patients received the intended four cycles (GCa, 64\%; MIC, 61\%). There was a significant survival advantage for GCa compared with MIC (hazard ratio, $0.76 ; 95 \% \mathrm{Cl}, 0.61$ to $0.93 ; P=.008$ ). Median survival was 10 months with GCa and 7.6 months with MIC (difference, 2.4 months; $95 \% \mathrm{Cl}, 1.0$ to 4.0), and 1-year survival was $40 \%$ with GCa and 30\% with MIC (difference, $10 \% ; 95 \% \mathrm{Cl}, 3 \%$ to $18 \%)$. Overall response rates were similar (42\% for GCa v 41\% for MIC; $P=.84$ ). More thrombocytopenia occurred with $\mathrm{GCa}(P=.03)$, but this was not associated with increased hospital admission or fatality. GCa caused less nausea, vomiting, constipation, and alopecia and was associated with fewer admissions for administration and better quality of life.

\section{Conclusion}

In patients with advanced NSCLC, GCa chemotherapy was shown to be a better-tolerated treatment that conferred a survival advantage over MIC.

\section{J Clin Oncol 23:142-153. (C) 2005 by American Society of Clinical Oncology}

\section{INTRODUCTION}

The combination of mitomycin, ifosfamide, and cisplatin (MIC) is widely used in Europe for the treatment of non-small-cell lung cancer (NSCLC), and the combination has been shown by Cullen et $\mathrm{al}^{1}$ to improve me- dian survival by approximately 2 months compared with supportive care in patients with advanced disease. In that trial, the overall response rate to $\mathrm{MIC}$ was 31\% (complete response, 2\%; partial response, 29\%), but toxicity scores were not reported. ${ }^{1}$ In a study that compared three cisplatin-containing 
regimens in patients with stage IIIB or IV NSCLC, the response rate reported with MIC was $40 \% .{ }^{2}$ In this study, grade 3 and 4 neutropenia occurred in $21 \%$ of patients and grade 3 and 4 thrombocytopenia occurred in $10 \%$ of patients. ${ }^{2}$

New drugs that have activity with low toxicity include gemcitabine (difluorodeoxycytidine), a deoxycytidine ana$\log$ that is a pyrimidine antimetabolite whose mechanism of action has been well characterized. ${ }^{3}$ As a single agent, gemcitabine has response rates of $20 \%$ to $26 \%$ in advanced NSCLC. ${ }^{4}$ Preclinical studies suggest synergy between gemcitabine and cisplatin, ${ }^{5}$ and clinical studies have demonstrated higher response rates and longer survival with the combination than with gemcitabine alone. ${ }^{6}$

Carboplatin is more suitable for outpatient administration because prehydration is unnecessary, and it is less nephrotoxic and neurotoxic. Because of these advantages, and probable comparable efficacy, carboplatin is an attractive alternative to cisplatin for combination with gemcitabine. An initial phase I study demonstrated the feasibility of combining the drugs, with dose-limiting myelosuppression at a predicted carboplatin area under the curve (AUC) of 5.2 $\mathrm{mg} / \mathrm{mL} / \mathrm{min}$ on a 4 -week schedule with gemcitabine 1,000 $\mathrm{mg} / \mathrm{m}^{2}$ on days 1,8 , and $15 .^{7}$ Symptomatic toxicity was similar to single-agent gemcitabine, and grade 4 neutropenia and thrombocytopenia were not associated with any serious clinical sequelae. However, a subsequent phase II trial suggested unacceptable toxicity in the form of thrombocytopenia using this 4-week schedule. ${ }^{8}$ A 3-week schedule of carboplatin AUC 5 on day 1 and gemcitabine 1,250 $\mathrm{mg} / \mathrm{m}^{2}$ on days 1 and 8 is associated with less thrombocytopenia than the 4-week schedule and was being used with acceptable toxicity by Sederholm et $\mathrm{al}^{9}$ of the Swedish Lung Cancer Group, who have subsequently presented data demonstrating superior survival with this combination compared with gemcitabine alone.

For the current trial, we selected a 3-week schedule of gemcitabine in combination with carboplatin (GCa) to compare with MIC, which was then the London Lung Cancer Group standard regimen, in patients with advanced (stage IIIB or IV) NSCLC. The trial was a multicenter, randomized, phase III, open-label study to compare the regimens with respect to survival, response rate, toxicity, and quality of life (QOL).

\section{PATIENTS AND METHODS}

\section{Eligibility Criteria}

Chemotherapy- and radiotherapy-naive patients with a histologic or cytologic diagnosis of stage IIIB or IV NSCLC and who were $\geq 18$ years old with measurable or nonmeasurable but assessable disease were eligible. Patients were required to have adequate bone marrow reserve (WBC count $\geq 3,000 / \mu \mathrm{L}$, platelet count $\geq 100,000 / \mu \mathrm{L}$, and hemoglobin $\geq 10 \mathrm{~g} / \mathrm{dL}$ ) and renal function adequate for chemotherapy $(>60 \mathrm{~mL} / \mathrm{min}$ where measured by
Cr-51-EDTA or $>50 \mathrm{~mL} / \mathrm{min}$ where measured by creatinine clearance or calculated by Cockroft and Gault formula ${ }^{10}$ ). A history of prior malignant tumor (unless there was no evidence of disease for at least 3 years or the tumor was a nonmelanoma skin tumor), a medical condition that excluded the use of chemotherapy, symptomatic brain metastases, or a life expectancy of less than 8 weeks rendered patients ineligible for trial entry. Approvals from the London Multi-Centre Research Ethics Committee and local research ethics committees were obtained for the trial, and all patients provided written informed consent.

\section{Treatment Allocation}

To randomly assign a patient, center staff completed a randomization checklist and telephoned the London Lung Cancer Group trials office. Patients were randomly allocated to receive GCa or MIC using a manual minimization procedure stratified by study center, stage (IIIB or IV), Eastern Cooperative Oncology Group (ECOG) performance status (0, 1, 2, or 3), histology (squamous, adenocarcinoma, or other NSCLC), sex, and age $(<70$ or $\geq 70$ years). The aim of minimization is to minimize any differences occurring by chance in the number of patients between the two treatment groups in the strata specified by the stratification factors above in each center.

Patients were randomly assigned to receive four cycles of GCa or MIC every 21 days. Gemcitabine has most frequently been used at a dose of $1,000 \mathrm{mg} / \mathrm{m}^{2}$ on days 1,8 , and 15 of a 4 -week cycle (ie, an average dose-intensity of $750 \mathrm{mg} / \mathrm{m}^{2} / \mathrm{wk}$ ). Because we used a 3 -week schedule, a gemcitabine dose of $1,200 \mathrm{mg} / \mathrm{m}^{2}$ on days 1 and 8 was given to maintain a dose-intensity of gemcitabine comparable to that of the 4-week regimen. Carboplatin AUC 5 was administered on day 1 after the gemcitabine infusion. We used the Calvert formula ${ }^{11}$ to determine the dose of carboplatin (in total milligrams) as follows: dose in $\mathrm{mg}=$ target AUC $\times$ (creatinine clearance +25$)$. The preferred methods for glomerular filtration rate (GFR) estimation were by Cr-51-EDTA or 24-hour urine collection; in these cases, an AUC of 5 was to be used (ie, $5 \times$ [GFR estimated by creatinine clearance +25$]$ ). If there were logistic problems in using either of these methods, GFR could be estimated by calculation (Cockroft and Gault formula ${ }^{10}$ ), and an AUC of 6 was then recommended because of the approximately $10 \%$ underestimation of $\mathrm{GFR}^{12}$ with this method (ie, $6 \times[\mathrm{GFR}$ estimated by Cockroft and Gault +25$])$. Both gemcitabine and carboplatin were given intravenously (IV) over 30 minutes.

Patients on the control arm (MIC) received mitomycin 6 $\mathrm{mg} / \mathrm{m}^{2}$ (into a fast-running drip), ifosfamide $3 \mathrm{~g} / \mathrm{m}^{2}$ (in $1 \mathrm{~L}$ of normal saline over 3 hours), and cisplatin $50 \mathrm{~g} / \mathrm{m}^{2}$ (in $500 \mathrm{~mL}$ of normal saline over 1 hour) IV on day 1 . Mesna $1.5 \mathrm{~g} / \mathrm{m}^{2}$ (in $1 \mathrm{~L}$ of normal saline with $20 \mathrm{mmol}$ of $\mathrm{KCl}$ over 4 hours) was also to be given after the cisplatin.

The protocol required all patients to receive prophylactic trimethoprim (or alternative antibiotics according to local preference in some centers) from day 8 to day 21 of each cycle to minimize the risk of neutropenic sepsis and respiratory infection. Suggested antiemetics were granisetron $3 \mathrm{mg}$ IV and dexamethasone $8 \mathrm{mg}$ IV before day 1 chemotherapy, metoclopramide $20 \mathrm{mg}$ IV before day 8 gemcitabine, and metoclopramide $10 \mathrm{mg}$ as required at other times.

Recommended dose modifications were based on pretreatment blood tests. For a WBC count of 1,500 to $2,999 / \mu \mathrm{L}$ or a platelet count of 50,000 to $99,999 / \mu \mathrm{L}$, all drugs were given at $75 \%$ of the full dose. For a WBC count less than $1,500 / \mu \mathrm{L}$ or a platelet count less than $50,000 / \mu \mathrm{L}$, doses of all drugs were delayed by 1 
week. If on day 8 of treatment the WBC count was less than $2,000 / \mu \mathrm{L}$ or the platelet count was less than $50,000 / \mu \mathrm{L}$, the day 8 gemcitabine dose was omitted. For a creatinine clearance of 40 to $60 \mathrm{~mL} / \mathrm{min}$, cisplatin and gemcitabine were reduced by $50 \%$; if the creatinine clearance was less than $40 \mathrm{~mL} / \mathrm{min}$, cisplatin and gemcitabine doses were omitted.

Use of thoracic or other radiotherapy after completion of chemotherapy and use of second-line chemotherapy were left to the discretion of treating clinicians.

\section{Assessments at Baseline, During Treatment, and During Follow-Up}

Patients were assessed at baseline and at each attendance for chemotherapy, then every 4 weeks for the first year and thereafter at 8 -week intervals. Assessments at baseline and during treatment included history and physical examination (including weight and height), ECOG performance status, and full blood count. Minimum baseline imaging consisted of chest radiograph and, if the lesion could not be assessed by this method, computed tomography (CT) of the thorax, CT or ultrasound of the abdomen, and, if clinically indicated, CT brain and isotope bone scan.

Toxicities were assessed according to National Cancer Institute Common Toxicity Criteria after each cycle (version 2.0, revised 1994). The worst grade since the last treatment was recorded on trial forms. Patients were evaluated for response at the start of each cycle by chest radiograph. When disease was measurable or assessable only by CT of the thorax, the scan was repeated after every second cycle. Extrapulmonary sites were reassessed by appropriate imaging methods after completion of chemotherapy. WHO criteria were used to define response. ${ }^{13}$ Disease status and any additional anticancer treatment were reported at each follow-up visit.

QOL was assessed using the European Organization for Research and Treatment of Cancer Quality of Life Questionnaire C30 (EORTC QLQ-C30) ${ }^{14}$ with lung cancer module LC-17 ${ }^{15}$ and the London Lung Cancer Group daily diary card. ${ }^{16,17}$ EORTC questionnaires were completed by the patient at baseline (before knowledge of the outcome of randomization), 3 weeks after the start of each cycle, and at the first two follow-up visits. Patients completed the daily diary card at baseline and then every evening from the first day of chemotherapy until 3 weeks after completion of the last course, scoring each of eight items using a four-point categoric scale.

\section{Statistical Design and Methods}

Power calculations. The primary outcome measure of the study was overall survival. Our aim was to determine whether GCa could confer a survival advantage comparable to that conferred by MIC but with less toxicity and better QOL. With an estimated 1-year survival rate of $28 \%$ in the MIC group, a total of 387 patients (193 events) would allow us to reliably ( $80 \%$ power, $95 \%$ CI) exclude the possibility that 1-year survival with GCa would be more than $10 \%$ worse than with MIC.

For QOL, allowing for $40 \%$ noncompliance, 232 patients conferred approximately $90 \%$ power to detect a difference between the treatment groups of $20 \%$ or greater in the proportion of patients crossing a threshold score on a QOL measure.

Analysis of results. We compared Kaplan-Meier curves for overall survival and progression-free survival using the standard log-rank test. The Cox proportional hazards regression model adjusted by the stratification factors (performance status, age, sex, stage, and cell type) was also applied. Overall survival was defined as the time from randomization to death from any cause; patients known to be still alive at the time of the analysis were censored at the time of their last follow-up. Progression-free survival was defined as the time from randomization to first appearance of progressive disease or death from any cause; patients known to be alive and without progressive disease at the time of analysis were censored at the time of their last follow-up. The relative benefits in overall survival and progression-free survival were assessed in an exploratory manner in subgroups defined by the stratification factors using a $\chi^{2}$ test $^{18}$ for interaction (if the factor is a categoric variable) or a $\chi^{2}$ test for trend (if the factor is an ordinal variable). The results are presented in Forest plots. For each factor, the results for each subgroup are displayed. Alongside the subgroup, the results are the number of deaths and the number of patients randomly assigned to each of the treatment groups; the estimate of the hazard ratio (using a center of black square) and CIs are around the estimate. The size of the square is proportional to the amount of information in that subgroup, so the larger the square, the more deaths have occurred in that subgroup. The $\chi^{2}$ test was used in the response (complete response plus partial response) rate comparison. The Mann-Whitney test for ordinal data was applied for the toxicity analysis.

EORTC QOL questionnaires were analyzed using recommended scoring scales and items. Forms with less than $80 \%$ of questions completed and scales with less than $50 \%$ of items completed were excluded. Raw scores for the scales and items of the questionnaires were compared at specified time points, and comparison of changes between baseline and selected time points were made using the Mann-Whitney test for ordinal data. Scores were also compared by calculation of the area under the score-time curve over the treatment period. The symptom score recorded by the diary card over time was plotted to display the changes over time. The mixed model for repeated measurements using PROC NLMIXED in SAS (SAS Institute, Cary, NC) was applied in an exploratory manner for the two treatment comparisons. ${ }^{19-22}$ This was implemented by fitting an ordinal probit model for each symptom. The treatment allocation and assessment time point were included in the linear predictor, and a general log likelihood specification was used in the MODEL statement.

All analyses were done on an intention-to-treat basis except for the analyses of response, toxicity, and daily diary cards, which were restricted to all patients who received at lease one cycle of allocated treatment. All $P$ values are two-sided.

\section{RESULTS}

\section{Patient Characteristics}

Patients were recruited between February 1999 and August 2001 from 24 centers in the United Kingdom. On the recommendation of the Independant Data Monitoring and Ethics Committee, the study recruited beyond the 387 patient target and closed with 422 patients, with 212 patients randomly assigned to GCa and 210 patients randomly assigned to MIC (Fig 1). The two arms were reasonably well balanced with respect to baseline characteristics (Table 1). By chance, there were small nonsignificant excesses of stage IV and of performance status 0 to 1 patients in the GCa arm. On review, five patients were found not to have met entry criteria (three patients did not have NSCLC, one patient 


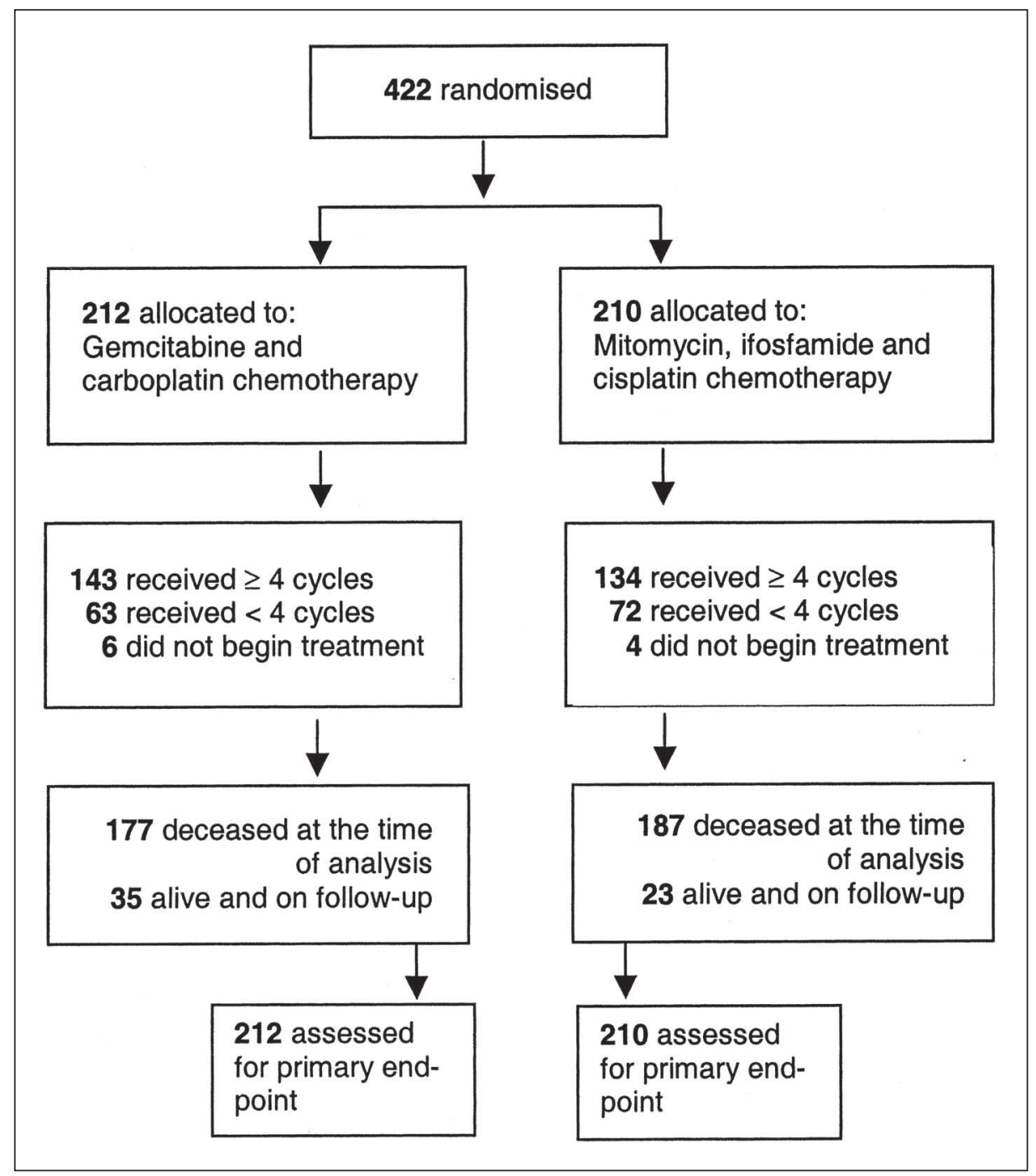

Fig 1. Trial profile.

had NSCLC concurrent with other cancer, and one patient did not stage IIIB/IV) but were included in the intentionto-treat survival analyses.

\section{Survival}

At the time of analysis, 364 patients (86\%) had died, and $17 \%$ of patients randomly assigned to GCa and $11 \%$ randomly assigned to MIC remained alive. The median follow-up for survivors was 18 months (range, 13 to 40 months). Lung cancer was the predominant cause of death ( $90 \%$ for GCa; $91 \%$ for MIC).

There was a survival benefit in favor of patients who received GCa (hazard ratio, 0.76 ; $95 \%$ CI, 0.61 to 0.93 ; $\log$-rank test $P=.008$; Fig 2). This translates into an improvement of $10 \%$ in 1-year survival compared with patients who received MIC $(40 \% v 30 \%$; $95 \%$ CI for difference, $3 \%$ to $18 \%)$, and $6 \%$ in 2 -year survival $(12 \% v$ $6 \%$; $95 \%$ CI for difference, $1 \%$ to $12 \%)$. For median survival, the hazard ratio translates into a difference of 2.4 months (10 $v 7.6$ months; 95\% CI for difference, 1.0 to 4.0 months). Because of the small imbalance in baseline characteristics of performance status and stage, the logrank test was also recalculated stratified by the variables used in minimization (performance status, age, sex, stage, and cell type). The result was unaffected (adjusted Cox model $P=.004$ ). Exclusion of the five patients subsequently found to have not met entry criteria did not affect the conclusions.

Forest plots showing exploratory subgroup analyses (Fig 3) indicate that the survival advantage of GCa over MIC applied regardless of age, sex, performance status, stage, and cell type.

There was no significant difference in progression-free survival (hazard ratio, $0.9 ; 95 \%$ CI, 0.74 to 1.09 ; log-rank $P=.28$; Fig 4). Median progression-free survival was 5.3 months with GCa and 4.8 months with MIC (difference, 0.5 months; $95 \% \mathrm{CI},-0.5$ to 1.4 months). 


\begin{tabular}{|c|c|c|c|c|}
\hline & \multicolumn{2}{|c|}{$\begin{array}{c}\text { GCa } \\
(\mathrm{n}=212)\end{array}$} & \multicolumn{2}{|c|}{$\begin{array}{c}\text { MIC } \\
(n=210)\end{array}$} \\
\hline & $\begin{array}{l}\text { No. of } \\
\text { Patients }\end{array}$ & $\%$ & $\begin{array}{l}\text { No. of } \\
\text { Patients }\end{array}$ & $\%$ \\
\hline \multicolumn{5}{|l|}{ Age, years } \\
\hline Median & \multicolumn{2}{|c|}{62} & \multicolumn{2}{|c|}{63} \\
\hline Range & \multicolumn{2}{|c|}{$40-81$} & \multicolumn{2}{|c|}{$34-81$} \\
\hline \multicolumn{5}{|l|}{ Sex } \\
\hline Male & 147 & 69 & 149 & 71 \\
\hline Female & 65 & 31 & 61 & 29 \\
\hline \multicolumn{5}{|c|}{ ECOG performance status } \\
\hline 0 & 64 & 30 & 44 & 21 \\
\hline 1 & 124 & 58 & 133 & 63 \\
\hline 2 & 19 & 9 & 29 & 14 \\
\hline 3 & 5 & 2 & 4 & 2 \\
\hline \multicolumn{5}{|l|}{ Stage } \\
\hline$\| \mathrm{IIB}$ & 95 & 45 & 105 & 50 \\
\hline IV & 117 & 55 & 105 & 50 \\
\hline \multicolumn{5}{|l|}{ Cell type } \\
\hline Squamous & 85 & 40 & 89 & 42 \\
\hline Adenocarcinoma & 79 & 37 & 70 & 33 \\
\hline Other NSCLC & 48 & 23 & 51 & 24 \\
\hline \multicolumn{5}{|c|}{$\begin{array}{l}\text { NOTE. The } P \text { values for patient characteristics were } .65, .72, .07, .29 \\
\text { and } .70 \text { for age, sex, performance status }(0 \text { to } 1 v 2 \text { to } 3) \text {, stage, and cel } \\
\text { type, respectively, using } \chi^{2} \text { test for frequency except for age, for which } \\
\text { a } t \text { test was used. } \\
\text { Abbreviations: GCa, gemcitabine and carboplatin; MIC, mitomycin } \\
\text { ifosfamide, and cisplatin; ECOG, Eastern Cooperative Oncology Group } \\
\text { NSCLC, non-small-cell lung cancer. }\end{array}$} \\
\hline
\end{tabular}

\section{Response to Treatment}

Best overall response rates (complete and partial response) to chemotherapy were very similar $(P=.84)$ between the two regimens (Table 2). Response rates for the 206 patients on each arm who received at least one course of

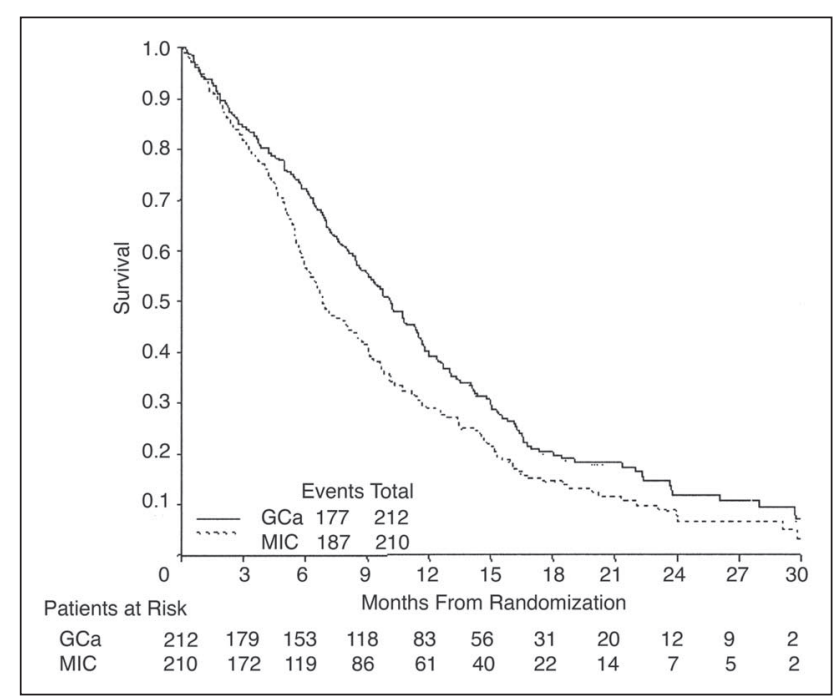

Fig 2. Overall survival. Hazard ratio $=0.76 ; 95 \% \mathrm{Cl}, 0.61$ to 0.93 ; log-rank $P=.008$. MIC, mitomycin, ifosfamide, and cisplatin; GCa, gemcitabine and carboplatin. chemotherapy were $42 \%$ (95\% CI, 35\% to $49 \%$ ) with GCa and $41 \%$ (95\% CI, $35 \%$ to $48 \%)$ with MIC.

\section{Treatment}

A majority of patients received four cycles of chemotherapy (64\% for GCa and 61\% for MIC). The reasons for stopping chemotherapy before four cycles were similar in the two arms, mainly progressive disease (GCa, $48 \%$; MIC, $50 \%$ ) and toxicity (GCa, 25\%; MIC, 24\%).

Delays and modifications were usually due to hematologic toxicity. The proportion of all cycles that were delayed (for 7 days or more) was 16\% with GCa and 9\% with MIC. The proportion of cycles modified was $16 \%$ with GCa and $9 \%$ with MIC. These differences occurred mainly because the day 8 chemotherapy on the GCa schedule doubled the opportunities for modification.

\section{Toxicity}

Two hundred six patients in each arm received at least one cycle of allocated chemotherapy. There was slightly more thrombocytopenia with GCa using a test for trend over the whole range of grades $(P=.03)$. This excess was largely due to increased occurrence of grade 2 thrombocytopenia, with no significant difference in frequency of grade 3 and 4 thrombocytopenia; thrombocytopenia was seldom symptomatic. There were no differences in anemia, leukopenia, and neutropenia (Table 3 ).

Nausea, vomiting, alopecia, and constipation were significantly worse with MIC. Rash and allergic reactions occurred more commonly with GCa, but nearly all were mild. There were no differences between the arms for infection, stomatitis, diarrhea, or anorexia (Table 4). No differences between the arms were seen for other toxicity items requested on data forms, including fever, myalgia, rigors, hematuria, and desquamation, which were all mild and occurred in less than 15\% of patients (not listed). Four deaths $(2 \%)$ on each arm were attributed wholly or in part to chemotherapy.

\section{Hospital Admissions}

Patients were admitted to the hospital overnight for the administration of $14 \%$ of GCa cycles and $90 \%$ of MIC cycles. Of the admissions related to GCa administration, $78 \%$ were for the first cycle. Of the patients receiving two or more cycles of GCa, $30 \%$ were admitted at least once between cycles, compared with $26 \%$ of patients receiving MIC. These admissions were predominantly related to toxicity (61\% of admissions for GCa; $52 \%$ of admissions for MIC).

\section{Additional Anticancer Therapy}

Thoracic radiotherapy was given after chemotherapy to $41(19 \%)$ of 212 patients who received GCa and to 34 (16\%) of 210 patients who received MIC $(P=.40)$. Doses of radiotherapy received varied greatly, with similar ranges in both arms (10 to 64 Gy for GCa; 10 to 66 Gy for MIC). Of 
Age

\begin{tabular}{cccrl}
\multicolumn{5}{c}{ (No.events/No. entered) } \\
GCa & MIC & O-E & Variance \\
\hline$\leq 70$ & $154 / 183$ & $151 / 172$ & -16.04 & 74.46 \\
$>70$ & $23 / 29$ & $36 / 38$ & -7.87 & 13.87 \\
\hline
\end{tabular}

Sex

\begin{tabular}{lccrl}
\multicolumn{5}{c}{ (No.events/No. entered) } \\
GCa & MIC & O-E & Variance \\
\hline Male & $123 / 147$ & $135 / 149$ & -19.98 & 63.14 \\
Female & $54 / 65$ & $52 / 61$ & -4.93 & 25.96 \\
\hline
\end{tabular}

ECOG performance status

\begin{tabular}{cccrl}
\multicolumn{5}{c}{ (No.events/No. entered) } \\
& GCa & MIC & O-E & Variance \\
\hline 0 & $44 / 64$ & $36 / 44$ & -5.29 & 18.81 \\
1 & $110 / 124$ & $120 / 133$ & -12.83 & 56.62 \\
2 & $18 / 19$ & $27 / 29$ & -2.06 & 10.82 \\
3 & $5 / 5$ & $4 / 4$ & -1.71 & 1.43
\end{tabular}

Stage

\begin{tabular}{lcccc}
\multicolumn{5}{c}{ (No.events/No. entered) } \\
GCa & MIC & O-E Variance \\
\hline Stage IIIb & $74 / 95$ & $89 / 105$ & -9.61 & 40.20 \\
Stage IV & $103 / 117$ & $98 / 105$ & -18.72 & 46.62
\end{tabular}

Cell type

\begin{tabular}{lcccc}
\multicolumn{5}{c}{ (No.events/No. entered) } \\
& GCa & MIC & O-E & Variance \\
\hline Squamous & $74 / 85$ & $75 / 89$ & -1.46 & 36.97 \\
Adeno & $63 / 79$ & $67 / 70$ & -11.71 & 31.09 \\
Other & $40 / 48$ & $45 / 51$ & -12.03 & 19.58
\end{tabular}

Hazard Ratio $(99 \% \mathrm{Cl})^{*}$
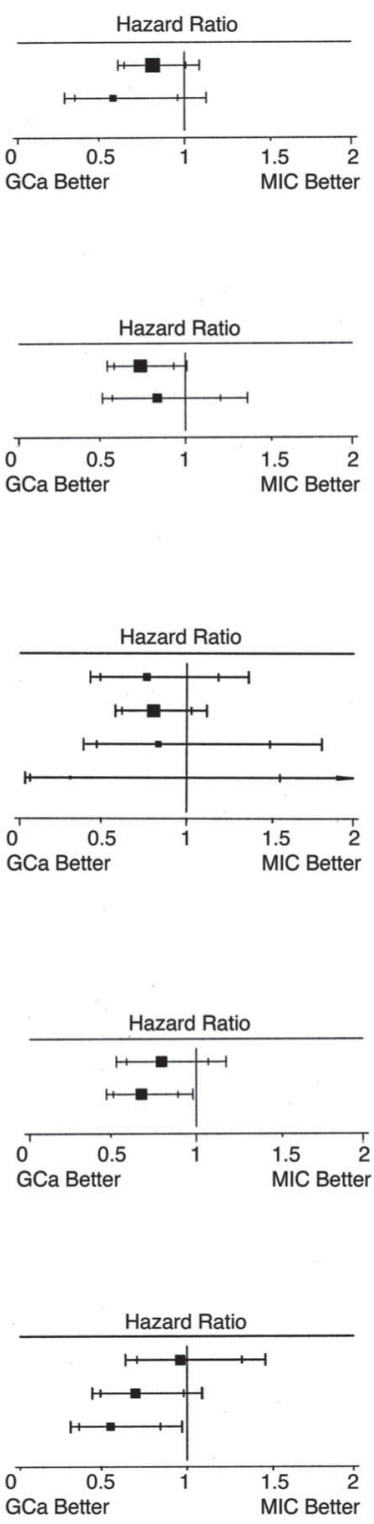

$P_{\mathrm{t}}=\cdot 23$

$P_{\mathrm{i}}=.59$

Fig 3. Subgroup analysis on overall survival. ( $P_{\mathrm{t}}$ test for trend, $P_{\mathrm{i}}$ test for interaction.) *Intermediate dashes within error bars $=95 \% \mathrm{Cl}$. MIC, mitomycin ifosfamide, and cisplatin; GCa, gemcitabine and carboplatin.

those who received thoracic radiotherapy, 14 (41\%) of 34 MIC patients compared with four (10\%) of $41 \mathrm{GCa}$ patients received doses of $50 \mathrm{~Gy}$ or more $(P=.03)$. Second-line chemotherapy was given to $18(8 \%)$ of $212 \mathrm{GCa}$ patients and to $12(6 \%)$ of 210 MIC patients $(P=.27)$. Docetaxel was the most commonly used agent.

\section{OOL}

Compliance with the QOL questionnaires was similar between the arms and decreased over time. Baseline ques- tionnaires were completed by $91 \%$ of patients on both arms; by 6 weeks, this had decreased to $79 \%$ on GCa and $83 \%$ on MIC, and by 12 weeks, this had decreased to $53 \%$ on GCa and $57 \%$ on MIC. All scales/items measured by EORTC QLQ-C30 and LC-17 questionnaires were well balanced across the two treatment groups at the pretreatment assessment. The most common symptoms present "quite a bit" or "very much" at baseline were cough in $45 \%$ of patients, fatigue in $42 \%$, and dyspnea in $40 \%$. 


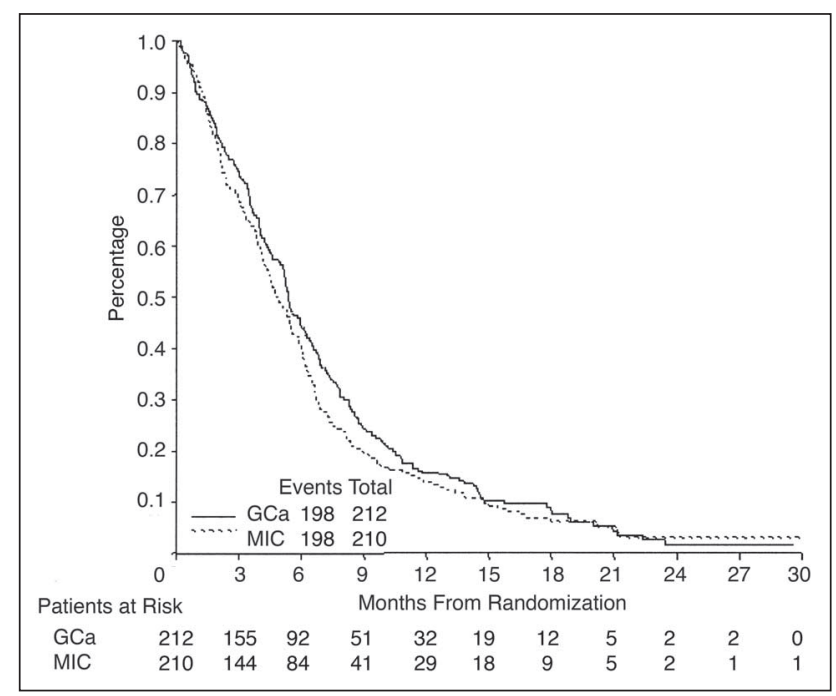

Fig 4. Progression-free survival. Hazard ratio $=0.9 ; 95 \% \mathrm{Cl}, 0.74$ to 1.09 ; log-rank $P=.28$. MIC, mitomycin, ifosfamide, and cisplatin; GCa, gemcitabine and carboplatin.

Comparison of changes in scores between baseline and 6 weeks showed significant advantages for GCa over MIC with respect to nausea and vomiting, appetite loss, constipation, fatigue, hair loss and being upset by hair loss, physical functioning, and role functioning (Table 5). Comparison of changes in scores between baseline and 12 weeks showed persistent significant advantages for GCa over MIC with respect to hair loss, nausea, and vomiting. AUC analyses over 12 weeks showed significant advantages for GCa with respect to hair loss, nausea, and vomiting (Table 5).

Diary cards were completed for 12 weeks. Compliance was high initially, with $78 \%$ of patients on GCa and $73 \%$ on

\begin{tabular}{|c|c|c|c|c|}
\hline & \multicolumn{2}{|c|}{$\begin{array}{c}\text { GCa } \\
(n=206)\end{array}$} & \multicolumn{2}{|c|}{$\begin{array}{c}\text { MIC } \\
(n=206)\end{array}$} \\
\hline & $\begin{array}{c}\text { No. of } \\
\text { Patients }\end{array}$ & $\%$ & $\begin{array}{c}\text { No. of } \\
\text { Patients }\end{array}$ & $\%$ \\
\hline CR & 3 & 1 & 9 & 4 \\
\hline PR & 84 & 41 & 76 & 37 \\
\hline SD & 76 & 37 & 75 & 36 \\
\hline PD & 28 & 14 & 32 & 15 \\
\hline NA & 15 & 7 & 14 & 7 \\
\hline \multicolumn{5}{|c|}{ Overall response rate, $\%$} \\
\hline$C R+P R$ & \multicolumn{2}{|c|}{42} & \multicolumn{2}{|c|}{41} \\
\hline $95 \% \mathrm{Cl}$ & \multicolumn{2}{|c|}{35 to 49} & \multicolumn{2}{|c|}{35 to 48} \\
\hline \multicolumn{5}{|c|}{$\begin{array}{l}\text { NOTE. Patients were deemed not assessable for response if their } \\
\text { response could not be determined because they died before reassess- } \\
\text { ment (MIC, } n=12 ; \mathrm{GCa}, \mathrm{n}=12 \text { ), were not reassessed (MIC, } \mathrm{n}=2 ; \mathrm{GCa} \text {, } \\
\mathrm{n}=2 \text { ), or had received intended chemotherapy but were later found to } \\
\text { have been inappropriately entered (GCa, } n=1 \text { ). } \\
\text { Abbreviations: GCa, gemcitabine and carboplatin; MIC, mitomycin, } \\
\text { ifosfamide, and cisplatin; CR, complete response; PR, partial response; } \\
\text { SD, stable disease; PD, progressive disease; NA, not assessable. }\end{array}$} \\
\hline
\end{tabular}

\begin{tabular}{|c|c|c|c|}
\hline \multirow[b]{2}{*}{$\begin{array}{l}\text { Reported Worst } \\
\text { Toxicity }\end{array}$} & \multicolumn{2}{|c|}{$\%$ of Patients } & \multirow[b]{2}{*}{$\begin{array}{c}P \\
\text { (Mann-Whitney) }\end{array}$} \\
\hline & $\begin{array}{c}\mathrm{GCa} \\
(\mathrm{n}=200 / 202)^{*}\end{array}$ & $\begin{array}{c}\text { MIC } \\
(n=201 / 202)^{*}\end{array}$ & \\
\hline \multicolumn{4}{|l|}{ Anemia, grade } \\
\hline 0 & 2 & 4 & .14 \\
\hline 1 & 26 & 32 & \\
\hline 2 & 61 & 54 & \\
\hline 3 & 7 & 8 & \\
\hline 4 & 2 & 1 & \\
\hline \multicolumn{4}{|l|}{ Leucopenia, grade } \\
\hline 0 & 27 & 24 & .30 \\
\hline 1 & 23 & 26 & \\
\hline 2 & 28 & 22 & \\
\hline 3 & 19 & 22 & \\
\hline 4 & 3 & 6 & \\
\hline \multicolumn{4}{|l|}{ Neutropenia, grade } \\
\hline 0 & 28 & 34 & .49 \\
\hline 1 & 13 & 12 & \\
\hline 2 & 24 & 21 & \\
\hline 3 & 21 & 18 & \\
\hline 4 & 13 & 15 & \\
\hline \multicolumn{4}{|c|}{ Thrombocytopenia, grade } \\
\hline 0 & 45 & 48 & .03 \\
\hline 1 & 28 & 38 & \\
\hline 2 & 3 & 6 & \\
\hline 3 & 11 & 4 & \\
\hline 4 & 13 & 3 & \\
\hline \multicolumn{4}{|c|}{$\begin{array}{l}\text { Abbreviations: GCa, gemcitabine and carboplatin; MIC, mitomycin, } \\
\text { ifosfamide, and cisplatin. } \\
\text { "A total of } 206 \text { patients in each arm received at least one course. Data } \\
\text { were unavailable for four patients on GCa for anemia, leukopenia, and } \\
\text { thrombocytopenia and for six patients for neutropenia and for four } \\
\text { patients on MIC for anemia, leukopenia, and neutropenia and five } \\
\text { patients for thrombocytopenia. }\end{array}$} \\
\hline
\end{tabular}

MIC completing cards during the first 3 weeks, but decreased over time. Plots of percentage of patients scoring greater than one for each of the eight questions are shown in Figure 5. All items except pain showed a trend in favor of GCa over MIC, but only nausea and vomiting reached statistical significance.

\section{DISCUSSION}

This trial demonstrates that GCa confers longer survival and is better tolerated than MIC in patients with advanced NSCLC. The consistency of the treatment effect across stage and performance subgroups strengthens confidence in the validity of the results. The median and 1-year survival (7.6 months, 30\%) for MIC was slightly better than previous results for this exact regimen in a United Kingdom trial comparing chemotherapy with no chemotherapy in patients with advanced disease (6.7 months and $25 \%),{ }^{1}$ so there is no reason to believe that spuriously poor results with MIC in the present study could explain the difference. The cisplatin dose used within the MIC regimen, although 


\begin{tabular}{|c|c|c|c|}
\hline Reported Worst Toxicity & $\begin{array}{c}\text { GCa } \\
(n=197)^{*}\end{array}$ & $\begin{array}{c}\mathrm{MIC} \\
(n=201 / 202)^{*}\end{array}$ & $\begin{array}{c}P \\
\text { (Mann-Whitney) }\end{array}$ \\
\hline \multicolumn{4}{|l|}{ Allergy, grade } \\
\hline 0 & 93 & 97 & .049 \\
\hline 1 & 5 & 2 & \\
\hline 2 & 1 & 1 & \\
\hline 3 & 1 & 0 & \\
\hline 4 & 0 & 0 & \\
\hline \multicolumn{4}{|l|}{ Nausea, grade } \\
\hline 0 & 36 & 23 & .0001 \\
\hline 1 & 37 & 35 & \\
\hline 2 & 22 & 29 & \\
\hline 3 & 5 & 12 & \\
\hline 4 & 0 & 1 & \\
\hline \multicolumn{4}{|l|}{ Vomiting, grade } \\
\hline 0 & 64 & 45 & $<.0001$ \\
\hline 1 & 20 & 26 & \\
\hline 2 & 12 & 19 & \\
\hline 3 & 3 & 8 & \\
\hline 4 & 1 & 2 & \\
\hline \multicolumn{4}{|l|}{ Alopecia, grade } \\
\hline 0 & 58 & 17 & $<.0001$ \\
\hline 1 & 36 & 26 & \\
\hline 2 & 6 & 48 & \\
\hline 3 & 1 & 9 & \\
\hline \multicolumn{4}{|l|}{ Rash, grade } \\
\hline 0 & 79 & 94 & $<.0001$ \\
\hline 1 & 14 & 3 & \\
\hline 2 & 7 & 2 & \\
\hline 3 & 1 & 0 & \\
\hline 4 & 0 & 0 & \\
\hline \multicolumn{4}{|l|}{ Constipation, grade } \\
\hline 0 & 52 & 39 & .005 \\
\hline 1 & 30 & 36 & \\
\hline 2 & 16 & 17 & \\
\hline 3 & 2 & 7 & \\
\hline 4 & 0 & 0 & \\
\hline \multicolumn{4}{|l|}{ Infection, grade } \\
\hline 0 & 70 & 72 & .54 \\
\hline 1 & 6 & 8 & \\
\hline 2 & 16 & 12 & \\
\hline 3 & 7 & 6 & \\
\hline 4 & 1 & 1 & \\
\hline \multicolumn{4}{|l|}{ Stomatitis, grade } \\
\hline 0 & 71 & 66 & .52 \\
\hline 1 & 18 & 27 & \\
\hline 2 & 10 & 5 & \\
\hline 3 & 1 & 2 & \\
\hline 4 & 0 & 0 & \\
\hline \multicolumn{4}{|l|}{ Diarrhea, grade } \\
\hline 0 & 82 & 83 & .67 \\
\hline 1 & 12 & 12 & \\
\hline 2 & 4 & 3 & \\
\hline 3 & 2 & 2 & \\
\hline 4 & 1 & 1 & \\
\hline \multicolumn{4}{|l|}{ Anorexia, grade } \\
\hline 0 & 51 & 51 & .50 \\
\hline 1 & 32 & 23 & \\
\hline 2 & 12 & 19 & \\
\hline 3 & 5 & 6 & \\
\hline 4 & 1 & 1 & \\
\hline \multicolumn{4}{|c|}{$\begin{array}{l}\text { Abbreviations: } \mathrm{GCa} \text {, gemcitabine and carboplatin; MIC, mitomycin, } \\
\text { ifosfamide, and cisplatin. } \\
\text { *A total of } 206 \text { patients in each arm received at least one course. Data } \\
\text { were unavailable for nine patients on GCa and four patients on MIC for } \\
\text { nausea, vomiting, alopecia, infection, stomatitis, and diarrhea and five } \\
\text { patients for allergy, rash, constipation, and anorexia. }\end{array}$} \\
\hline
\end{tabular}

lower than that generally used in the United States and Europe, is standard within the United Kingdom. The median and 1-year survival for GCa (10 months, 40\%) were comparable to those reported with a similar GCa regimen (11 months, 44\%) when compared with gemcitabine alone. ${ }^{9}$ Our 1-year survival with GCa was also similar to that reported with gemcitabine and cisplatin (36\%) in an ECOG trial, which found no significant survival differences between that regimen, cisplatin/paclitaxel (31\%), cisplatin/ docetaxel (31\%), and carboplatin/paclitaxel (34\%). ${ }^{23}$ Our study had a higher proportion of stage IIIB patients but also a higher proportion of performance status 2 or 3 patients than the ECOG study.

A smaller trial (307 patients) comparing a 4-week regimen of gemcitabine $1,000 \mathrm{mg} / \mathrm{m}^{2}$ on days 1,8 , and 15 plus cisplatin $100 \mathrm{mg} / \mathrm{m}^{2}$ day 2 with MIC using a higher dose of cisplatin $\left(100 \mathrm{mg} / \mathrm{m}^{2}\right)$ than we used $\left(50 \mathrm{mg} / \mathrm{m}^{2}\right)$ and giving six cycles rather than four resulted in no significant survival difference in median and 1-year survival between MIC (9.6 months, 34\%) and gemcitabine with cisplatin (8.6 months, $33 \%) .{ }^{24}$ It is possible that the higher dose of cisplatin may have conferred some survival advantage, although there is no randomized trial evidence that demonstrates that a dose of cisplatin greater than $50 \mathrm{mg} / \mathrm{m}^{2}$ confers a survival advantage in this regimen, and the higher dose did confer more frequent grade 3 or 4 hematologic toxicity than observed with MIC in our study. ${ }^{24} \mathrm{~A}$ randomized comparison of a 4-week regimen of gemcitabine $1,000 \mathrm{mg} / \mathrm{m}^{2}$ on days 1,8 , and 15 plus carboplatin AUC 5 on day 1 with either MIC or mitomycin, vinblastine, and cisplatin (MVP) found no significant survival difference, although QOL tended to favor GCa. ${ }^{25}$ It is possible that the survival advantage demonstrated for GCa in our study may relate to the use of a 3 -week rather than 4 -week schedule. The 3-week schedule confers a higher dose-intensity for carboplatin and leads less frequently to grade 3 to 4 thrombocytopenia and hence fewer gemcitabine omissions. It seems unlikely that the use of carboplatin rather than cisplatin with gemcitabine was responsible for the survival advantage over MIC. A large randomized phase III comparison of paclitaxel in combination with either carboplatin AUC 6 or cisplatin $80 \mathrm{mg} / \mathrm{m}^{2}$ found a 1.6-month median survival advantage for cisplatin in an extended follow-up but with more nausea, vomiting, and nephrotoxicity. ${ }^{26}$ A smaller randomized phase III comparison of a 3-week schedule of gemcitabine in combination with either carboplatin AUC 5 or cisplatin $80 \mathrm{mg} / \mathrm{m}^{2}$ showed no significant survival difference but more nausea and vomiting with cisplatin. ${ }^{27} \mathrm{~A}$ recent meta-analysis demonstrated that in combination with a platinum agent, gemcitabine confers a survival advantage over other agents, and this may be relevant. ${ }^{28}$

In our study, progression-free survival was not significantly better for GCa. The protocol required follow-up visits monthly for the first year and every 2 months thereafter, but in 


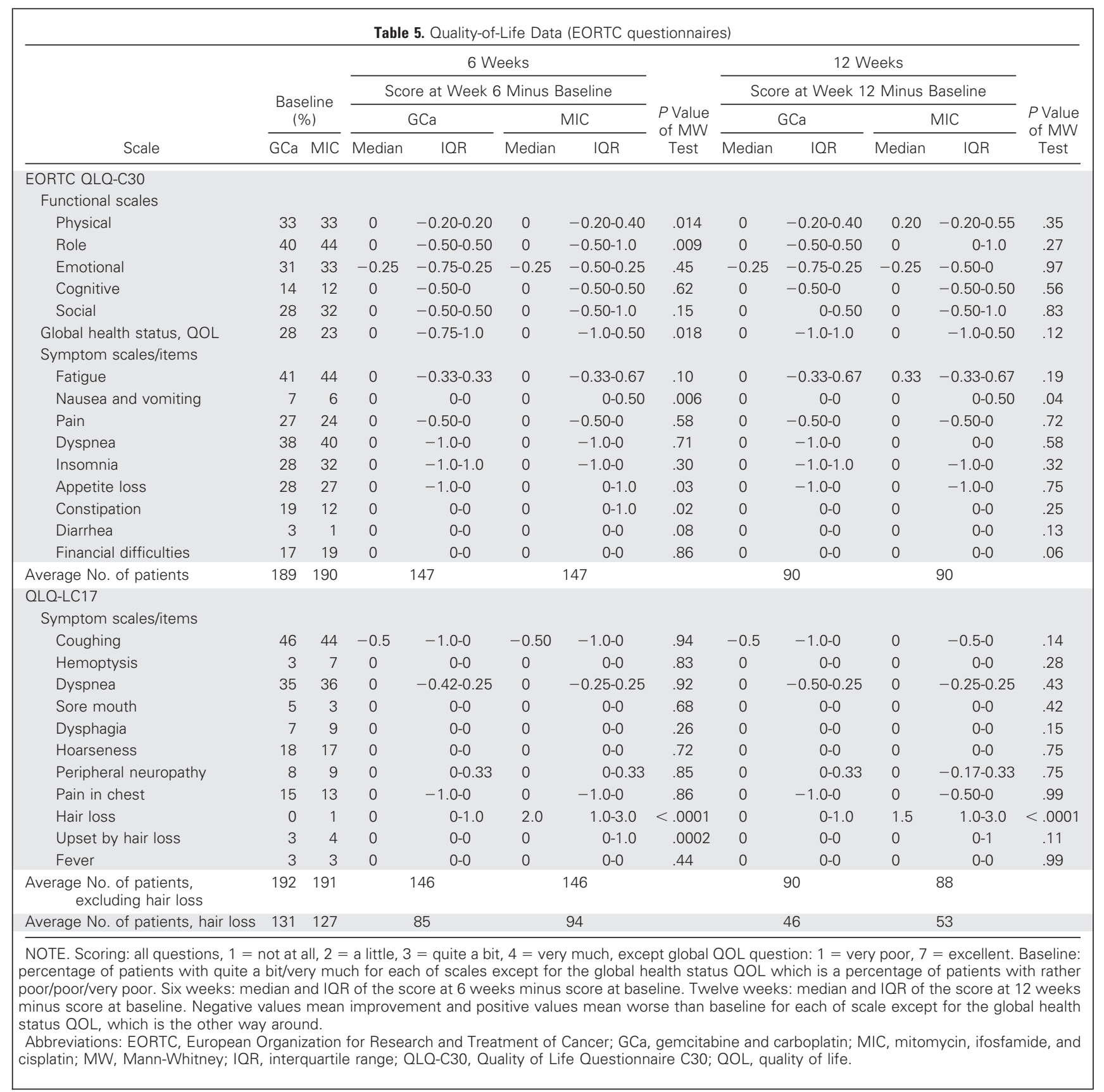

practice, intervals were often extended, making ascertainment of date of progression prone to inaccuracy. This may have resulted in underestimation of the difference between the arms. A few more patients in the GCa arm received additional treatment in the form of radiotherapy or second-line chemotherapy, but this was offset by a significantly greater proportion of patients receiving what could be deemed a radical dose (at least $50 \mathrm{~Gy}$ ) of thoracic radiotherapy in the MIC arm. Low-dose palliative radiotherapy does not prolong survival, and the survival advantage conferred by second-line chemother- apy is small at best, so it is implausible that these minor differences could account for the survival advantage for GCa.

GCa was associated with more thrombocytopenia, but there was no significant difference between the arms in frequency of hospital admission between chemotherapy cycles. Recorded full blood counts obtained pretreatment on day 1 , on day 8 for GCa, and where available at nadir were graded for toxicity. Nadir counts were not usually performed for patients receiving MIC, so that hematologic toxicity may have been under-reported in this arm. Symptomatic toxicities such as nausea and vomiting were less 

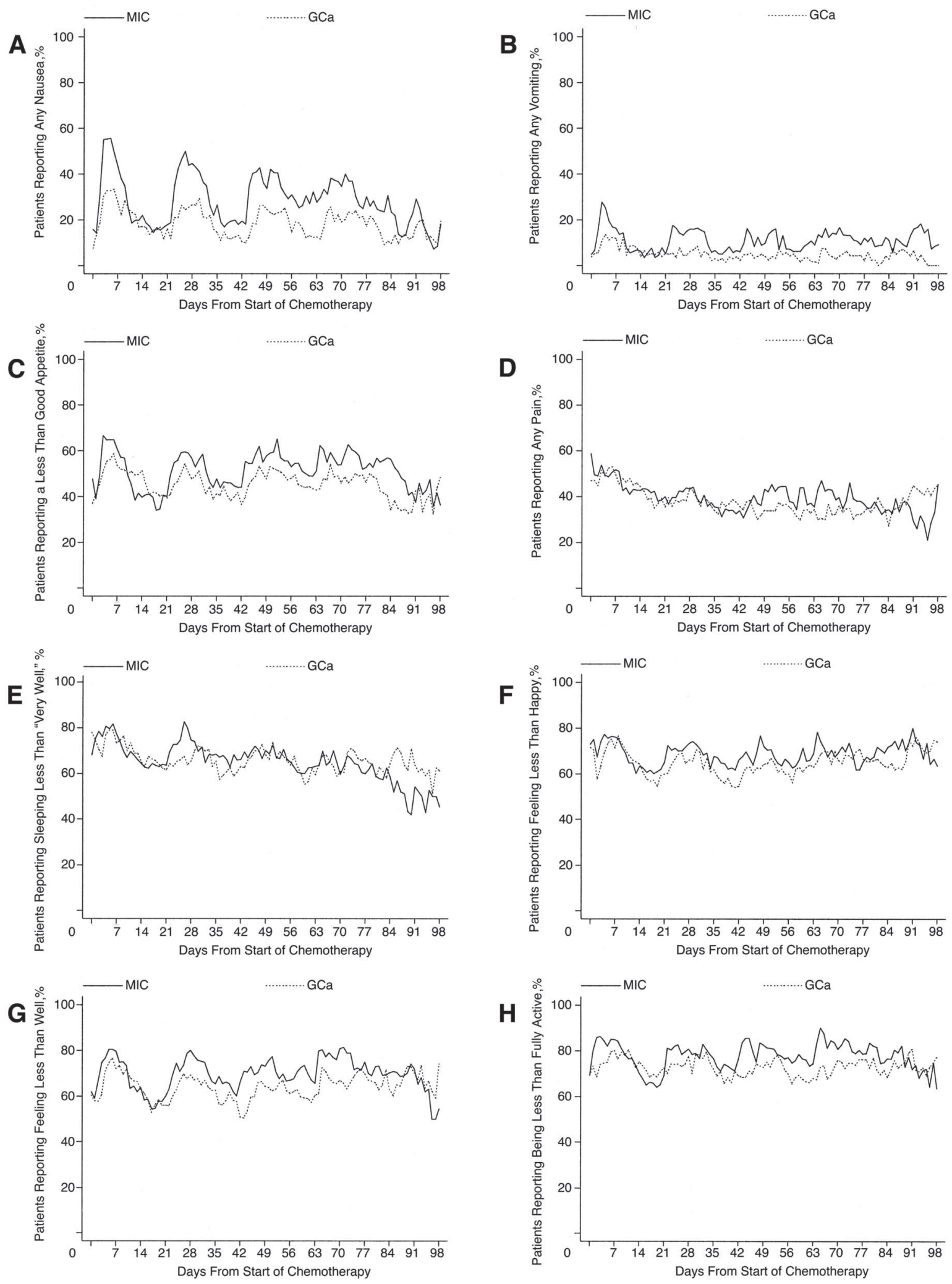

Fig 5. Daily diary card scores over time. Plots include all patients who completed daily diary cards and who received at least one cycle of chemotherapy. MIC mitomycin, ifosfamide, and cisplatin; GCa, gemcitabine and carboplatin. 
frequent with GCa, and significant hair loss rarely occurred with GCa. GCa was associated with overall better QOL as assessed by interval questionnaires and daily diary cards. Clinicians considered it desirable to admit patients overnight for administration of MIC far more frequently than GCa because of the hydration requirement for cisplatin administration. Most of the admissions for GCa were for the first cycle, at which time patients may already have been in hospital after completion of investigations. There may also have been caution regarding administration of the first course of a relatively new regimen.

There is increasing evidence that doublets using a platinum agent and one of the newer chemotherapeutic agents active in lung cancer achieve better results than older triplets. A Portuguese study compared the combination of MVP (like MIC, a widely used regimen in the United Kingdom and Europe) with cisplatin in combination with either gemcitabine or vinorelbine and found that both the latter regimens conferred longer survival than MVP. ${ }^{29}$ The United Kingdom National Institute for Clinical Excellence guidance for chemotherapy in NSCLC (June 2001) stated that objective assessment of new agents was hindered by the lack of good studies directly comparing the new agents in combination with platinum-based therapy with combination regimens commonly used in the United Kingdom (ie, MIC and MVP). ${ }^{30}$ Results from randomized studies are now available and favor the new agents over both these older regimens.

In patients with advanced NSCLC with limited life expectancy, the goals of chemotherapy are palliation of symptoms and modest prolongation of survival. In this setting, reducing hospital admissions and symptomatic toxicity are important aims. GCa is an effective and well-tolerated treatment that the London Lung Cancer Group now regards as its standard first-line regimen for stage IIIB or IV NSCLC and therefore as its reference regimen for future studies.

\section{Appendix}

Clinicians and researchers include the following (centers listed in order of contribution): St Bartholomew's Hospital, London (R.M. Rudd, J.P.C. Steele, J. Shamash, P. Wells, and M. Evans); Clatterbridge Centre for Oncology, Clatterbridge (J. Littler, E. Marshall, P.I. Clark, I. Syndikus, J.
Maguire, K. Hyatt, B. Haylock, S.M. O’Reilly, J. Reilly, and C. Ball); Weston Park Hospital, Sheffield (M. Hatton, P.C. Lorigan, P.M. Fisher, P. Joyce, R. Bell, Y. Charles, and J. Bliss); Southampton University Hospitals, Southampton (P.W.M. Johnson, C. Ottensmeier, T. Goldie, and C. Gradidge); Norfolk and Norwich and James Paget Hospitals (W.M.C. Martin, J. Oldman, J. Beety, N. Stevens, and K. Holland); Ninewells Hospital and Medical School (E.M. Rankin, M. Highley, and D. Forbes); Whittington Hospital, London (S.M. Lee, A. Leary, J. Ireland); North Middlesex Hospital (T. Eisen, H. Bridle, and K. O'Farrell); Guys and St Thomas National Health Service Trust (P.G. Harper, P. Ellis, J. Prendiville, T. Plunkett, A. Poole, and K. Saggers); Oldchurch Hospital (J. Shamash and L. Huckins); Southend Hospital (A. Lamont, C. Trask, and G. Ogden); University College Hospitals Trust, London (S.M. Lee, S.G. Spiro, and A. Leary); Sunderland Royal Hospital (I. Taylor, H.W. Clague, K.K. Sridharan, and J. Anderson); Stobhill Hospital, Glasgow (R. Milroy, J. McPhelim, and J. Graham); Edinburgh Cancer Centre (A. Price, J. Ironside, F.A. Little, F. Dawson, F. Peet, and D. Boyle); North Devon District Hospital (M. Napier, R. Ayres, and B. Holbrook); Cheltenham General Hospital (D. Farrugia, P. Jenkins, and J. Kellaway); St George's Hospital, London (J.L. Mansi and J. Clarke); Ysbyty Gwynedd, Bangor (N. Stuart and J. Jones); Royal Devon and Exeter Hospital (P. Bliss, M. Napier, C. Ridler, and D. Astill); Darlington Hospital (E.N. Evans and S.M. Alcock); Torbay Hospital (A. Goodman and F. Roberts); Royal Berkshire Hospital (P. Rogers and C. Lewis); and Mount Vernon Hospital (P. Ostler).

Trial center staff include the following: Nicole Gower, Paul Smith, Lindsay James, Susan Wan, and Katy O'Donnell.

\section{Authors' Disclosures of Potential Conflicts of Interest}

The following authors or their immediate family members have indicated a financial interest. No conflict exists for drugs or devices used in a study if they are not being evaluated as part of the investigation. Acted as a consultant within the past 2 years: R.M. Rudd, Eli Lilly; P.G. Harper, Eli Lilly. Received more than $\$ 2,000$ per year from a company for either of the past 2 years: T.G. Eisen, Eli Lilly; P.G. Harper, Eli Lilly; W.M.C. Martin, Eli Lilly.

\section{REFERENCES}

1. Cullen $M H$, Billingham LJ, Woodruffe $C M$ et al: Mitomycin, ifosfamide and cisplatin in unresectable non-small-cell lung cancer: Effects on survival and quality of life. J Clin Oncol 17:3188-3194, 1999

2. Crino L, Clerici M, Figoli F, et al: Chemotherapy of advanced non-small-cell lung cancer: A comparison of three active regimens-A randomized trial of the Italian Oncology Group for Clinical Research (G.O.I.R.C.). Ann Oncol 6:347-353, 1995
3. Hertel LW, Kroin JS, Misner JW, et al: Synthesis of 2-deoxy-2,2'-difluoro-D-ribose and 2-deoxy-2',2'-difluoro-D-ribofuranosyl nucleosides. J Org Chem 53:2406-2409, 1988

4. Sandler A, Ettinger DS: Gemcitabine: Singleagent and combination therapy in non-small cell lung cancer. Oncologist 4:241-251, 1999

5. Bergman AM, Ruiz van Haperen VW, Veerman G, et al: Synergistic interaction between cisplatin and gemcitabine in vitro. Clin Cancer Res 2:521-530, 1996

6. Sandler AB, Nemunaitis J, Denham $C$, et al: Phase III trial of gemcitabine plus cisplatin versus cisplatin alone in patients with locally advanced or metastatic non-smallcell lung cancer. J Clin Oncol 18:122-130, 2000

7. Carmichael J, Allerheiligen S, Walling J: A phase I study of gemcitabine and carboplatin in non-small cell lung cancer. Semin Surg Oncol 23:55-59, 1996

8. Ng EW, Sandler AB, Robinson $L$, et al: $A$ phase II study of carboplatin plus gemcitabine in advanced non-small-cell lung cancer (NSCLC): A Hoosier Oncology Group study. Am J Clin Oncol 22:550-553, 1999 
9. Sederholm C: Gemcitabine compared with gemcitabine plus carboplatin (GCa) in advanced non-small cell lung cancer (NSCLC): A phase III study by the Swedish Lung Cancer Study Group (SLUSG). Proc Am Soc Clin Oncol 21:291a, 2002 (abstr 1162)

10. Gault MH, Longerich LL, Harnett JD, et al: Predicting glomerular function from adjusted serum creatinine. Nephron 62:249-256, 1992

11. Calvert $A H$, Newell $D R$, Gumbrell $L A$, et al: Carboplatin dosage: Prospective evaluation of a simple formula based on renal function. J Clin Oncol 7:1748-1756, 1989

12. Gore $\mathrm{M}$ : Carboplatin equals cisplatin: But how do I prescribe it? J Clin Oncol 21:3183-3184, 2003

13. World Health Organization:WHO Handbook for Reporting Results of Cancer Treatment: WHO Offset Publication No. 48. Geneva, Switzerland, World Health Organization, 1979

14. Aaronson NK, Ahmedzai S, Bergman B, et al: The European Organization for Research and Treatment of Cancer QLQ-C303: A quality-of-life instrument for use in international clinical trials in oncology. J Natl Cancer Inst 85:365-376, 1993

15. Bergman B, Aaronson NK, Ahmedzai S, et al: The EORTC QLQ-LC13: A modular supplement to the EORTC core quality of life questionnaire (QLQ-C30) for use in lung cancer clinical trials. Eur J Cancer 30a:635-642, 1994

16. Geddes DM, Dones L, Hill E, et al: Quality of life during chemotherapy for small cell lung cancer: Assessment and use of a daily diary card in a randomised trial. Eur J Cancer 26:484-492, 1990
17. Gower NH, Rudd RM, Ruiz de Elvira MC, et al: Assessment of 'quality of life' using a daily diary card in a randomized trial of chemotherapy in small-cell lung cancer. Ann Oncol 6:575-580, 1995

18. Altman DG: Practical Statistics for Medical Research. London, United Kingdom, Chapman and Hall, 1991

19. Davidian M, Giltinan DM: Nonlinear Models for Repeated Measurement Data. New York NY, Chapman \& Hall, 1995

20. Diggle PJ, Liang KY, Zeger SL: Analysis of longitudinal data. Oxford, United Kingdom, Clarendon Press, 1994

21. Vonesh EF, Chinchilli VM: Linear and Nonlinear Models for the Analysis of Repeated Measurements. New York, NY, Marcel Dekker, 1997

22. Qian W, Parmar MKB, Sambrook RJ, Fayers et al: Analysis of messy longitudinal data from a randomized clinical trial. Stat Med 19 2657-2674, 2000

23. Schiller JH, Harrington $D$, Belani $C P$, et al: Comparison of four chemotherapy regimens for advanced non-small-cell lung cancer. N Engl J Med 346:92-98, 2002

24. Crino L, Scagliotti GV, Ricci S, et al: Gemcitabine and cisplatin versus mitomycin, ifosfamide and cisplatin in advanced non-small cell lung cancer: A randomized phase III study of the Italian Lung Cancer Project. J Clin Oncol 17: 3522-3530, 1999

25. Danson S, Middleton MR, O'Byrne KJ, et al: Phase III trial of gemcitabine and carboplatin versus mitomycin, ifosfamide, and cisplatin or mitomycin, vinblastine, and cisplatin in patients with advanced non-small cell lung carcinoma Cancer 98:542-553, 2003

26. Rosell R, Gatzmeier U, Betticher DC, et al: Phase III randomized trial comparing paclitaxel/ carboplatin with paclitaxel/cisplatin in patients with advanced non-small-cell lung cancer: A cooperative multinational trial. Ann Oncol 13:1539 1549, 2002

27. Zatloukal $P$, Petruzelka L, Zermanova $M$, et al: Gemcitabine plus cisplatin versus gemcitabine plus carboplatin in stage IIIB and IV non-small cell lung cancer: A phase III randomized trial Lung Cancer 41:321-331, 2003

28. Le Chevalier T, Brown A, Natale R, et al: Gemcitabine in the treatment of non-small cell lung cancer (NSCLC): A meta-analysis of survival and progression-free survival data. Lung Cancer 41:S70, 2003 (suppl 2; abstr 0-239)

29. Melo MJ, Barradas $P$, Costa $A$, et al: Results of a randomised phase III trial comparing 4 cisplatin (P)-based regimens in the treatment of locally advanced and metastatic nonsmall cell lung cancer (NSCLC): Mitomycin/ cisplatin (MVP) is no longer a therapeutic option. Proc Am Soc Clin Oncol 21:302a, 2002 (abstr 1205)

30. National Institute for Clinical Excellence: Guidance on the use of Docetaxel, Paclitaxel, Gemcitabine and Vinorelbine for the Treatment of Non-Small Cell Lung Cancer: Technology Appraisal Guidance No. 26. London, UK, National Institute for Clinical Excellence, 2001

\section{Attention Authors: You Asked For It - You Got It! \\ Online Manuscript System Launched November 1st}

On November 1st, JCO formally introduced its online Manuscript Processing System that will improve all aspects of the submission and peer-review process. Authors should notice a quicker turnaround time from submission to decision through this new system.

Based on the well known Bench>Press system by HighWire Press, the JCO Manuscript Processing System promises to further JCO's reputation of providing excellent author service, which includes an already fast turnaround time of 7 weeks from submission to decision, no submission fees, no page charges, and allowing authors to freely use their work that has appeared in the journal.

JCO's Manuscript Processing System will benefit authors by

- eliminating the time and expense of copying and sending papers through the mail

- allowing authors to complete required submission forms quickly and easily online

- receiving nearly immediate acknowledgement of receipt of manuscripts

- tracking the status of manuscripts at any time online and

- accessing all reviews and decisions online.

Authors are encouraged to register at http://submit.jco.org

For more details on JCO's new online Manuscript Processing System, go online to http://www.jco.org/misc/announcements.shtml. Also, watch upcoming issues of JCO for updates like this one. 